\title{
AC 2009-35: STARTING FROM SCRATCH: A SUMMARY OF EXPERIENCES IN THE FIRST YEAR OF THE COLLABORATIVE ELECTRICAL ENGINEERING PROGRAM BETWEEN MISSOURI UNIVERSITY OF SCIENCE AND TECHNOLOGY AND MISSOURI STATE UNIVERSITY
}

\section{Robert Egbert, Missouri State University}

Dr. Robert Egbert is Professor of Electrical Engineering at Missouri State University (MSU) in Springfield, MO. He received B.S., M.S., and Ph.D. degrees from the University of Missouri Rolla (now Missouri University of Science and Technology - Missouri S\&T) in 1972, 1973, and 1976, respectively. He has industrial experience with Black \& Veatch Consulting Engineers in Kansas City and MKEC Engineering Consultants in Wichita, KS. He was a member of the faculty of the Department of Electrical and Computer Engineering at Wichita State University for over 20 years. In July 2008, he joined the faculty of Missouri State University (MSU) in Springfield, $\mathrm{MO}$ as the first MSU faculty member in the new (Missouri S\&T/MSU) collaborative engineering program. 


\section{Starting from "Scratch" - A Summary of Experiences in the First Year of the Collaborative Electrical Engineering Program between Missouri University of Science and Technology and Missouri State University}

\section{Introduction}

Over the past several years, economic growth in southwest Missouri in general, and in the vicinity of Springfield, Missouri, in particular, has led to an increased demand for engineers in this region. As the area grew, engineering firms and other employers of engineers in southwest Missouri began to express concerns about the availability of engineering graduates. A survey indicated that the two fields of most demand in southwest Missouri were Civil and Electrical Engineering.

The nearest university engineering program was in Rolla, Missouri at Missouri University of Science \& Technology (Missouri S\&T), formerly the University of Missouri at Rolla. Missouri State University (MSU), at Springfield, had a pre-engineering program which allowed students to take classes in engineering fundamentals at MSU for two years and then transfer to Rolla. However, in spite of the demand for engineers, the cost of developing a stand-alone engineering program at MSU seemed cost prohibitive and needlessly redundant with Missouri S\&T relatively close to Springfield.

Ultimately, with the support of the regional engineering community, officials from the two schools began to meet to discuss the development of a collaborative engineering program.

This culminated on August 21, 2006, when Missouri Governor Matt Blunt, along with the Curators of the University of Missouri, the Chancellor of Missouri University of Science and Technology (Missouri S\&T), and the President of Missouri State University (MSU) signed a Memorandum of Understanding that allowed Missouri S\&T to offer bachelor's degrees in Civil and Electrical Engineering on the MSU campus.

\section{Memorandum of Understanding}

Key issues in the Memorandum of Understanding were:

1. The degrees in both Civil and Electrical Engineering will be Missouri S\&T degrees and will be the same degree programs as are already offered on the Rolla campus. The diplomas will read Missouri University of Science and Technology in cooperation with Missouri State University.

2. The degree programs will be ABET accredited.

3. Courses in the program will be offered through a combination of on-site and internet delivery. Courses will be taught by a combination of Missouri S\&T and MSU faculty. 
4. New MSU engineering faculty will be hired through a committee consisting of both MSU and Missouri S\&T faculty members.

5. Student support services will be provided by MSU. Missouri S\&T will provide an onsite Director for advising and coordination.

6. Students entering the program must first satisfy the MSU admission requirements, then after two years, the students will be formally admitted to the appropriate Missouri S\&T engineering program based on Missouri S\&T admission criteria.

7. Tuition for the pre-engineering and elective courses offered by MSU will be set at MSU rates. Tuition rates for engineering courses will be set at Missouri S\&T rates. MSU will collect tuition and fees for the engineering courses and send the money to Missouri S\&T. Missouri S\&T will reimburse MSU for engineering courses taught by MSU faculty.

8. Department chairs in the Civil and Electrical Engineering programs at Missouri S\&T will provide administrative oversight of the respective programs.

9. The programs will be jointly reviewed by Missouri S\&T and MSU every three years.

Special one-time state funding provided monies for the procurement of laboratory equipment, the remodeling of rooms on the MSU campus to make laboratory space for the two new programs, and for the recruitment of new faculty.

\section{Collaborative Engineering Programs Elsewhere}

Collaborative engineering programs are certainly not a new phenomenon, see for example ${ }^{1}$ A literature search revealed the existence of a number of collaborative engineering programs at various institutions throughout the US*

Some of these are the so called " $2+2$ programs," where students enroll for two years at one institution and typically take their basic mathematics, chemistry, physics, and general education courses before transferring to a second institution where they are assimilated into an existing engineering program. This is similar to the pre-engineering program that existed between Missouri S\&T and MSU before the collaborative engineering program was established.

The other type of collaborative programs are those that offer a full four year B.S. degree in one of more engineering disciplines at one institution in collaboration with an established engineering program at a second institution. In these programs, the engineering courses are generally taught by: 1) faculty or adjuncts at the satellite institution, 2) faculty from the parent institution who personally travel to the site of the satellite program, 3) faculty from the parent institution through an interactive video network, or 4) some combination of these other alternatives. 
Many of these four-year collaborative programs involve two institutions in the same university system. This can make a collaborative program easier to implement in that many policies are the same at the two participating institutions.

When two entirely separate institutions attempt to set up a collaborative program, such as the case described here with Missouri S\&T and MSU, there can be more obstacles to overcome as is described in the next section.

\section{Institutional Issues and Problems}

Following the signing of the Memorandum of Understanding, key administrative personnel from the two institutions formed a joint committee and began a series of meetings aimed at implementing the provisions of the agreement. The joint committee was able to resolve many of the major institutional issues and problems, including the following:

Admission:

Students first apply and are admitted to MSU through the normal MSU admissions process when enrolling in MSU courses. Prior to taking a Missouri S\&T course as part of the program, the student must apply and be admitted to Missouri S\&T. Students will be admitted to Missouri S\&T as "distance transfer students". The special designation will allow the Missouri S\&T registrar to identify the students in the Collaborative Engineering program.

Missouri S\&T had a requirement that the last 60 hours of an undergraduate program normally be taken in residence at Missouri S\&T. This requirement was waived for students in the collaborative program at MSU.

For tuition purposes, "engineering courses," as discussed in Item 7 of the Memorandum of Understanding were defined by the committee as all engineering courses in the sophomore, junior, and senior years normally offered by Missouri S\&T.

In terms of scholarships and financial aid, the joint committee decided that MSU will be the "home institution" for students at MSU enrolled in the collaborative program. Any add/drop activity by a student in the collaborative program will be reported to the MSU financial aid office by the Registrar's office at Missouri S\&T. Students on scholarship in the collaborative engineering program will be required to meet and maintain the MSU scholarship renewal criteria. Funding for the scholarships has been a difficult issue, and at this point in time it has not been resolved. Scholarship programs at the two universities are different, and it is difficult to decide how the MSU scholarships would be applied toward tuition for the Missouri S\&T engineering courses.

The joint committee decided that students in the collaborative program who drop a class will have their tuition refunded in accordance with the MSU refund schedule. Provisions were also made to allow other MSU students, who were not in the collaborative program, but who wished 
to take one or more of the engineering classes offered, provided they had the required prerequisites.

Other issues still being resolved by the joint committee include, procedures for handling international students, Veterans Administration students and student athletes, the determination of which school calendar to follow, procedures for students to obtain official transcripts, and which commencement ceremony to attend.

Personnel from the MSU and Missouri S\&T Libraries also met to discuss interlibrary loan issues. It was generally agreed that students in the collaborative engineering programs on the MSU campus should have access to the holdings at the Missouri S\&T Library. Unfortunately the two institutions were members to two different interlibrary circulation associations. This was resolved though a series of agreements.

\section{Curriculum Issues and Problems}

General Education requirements at the two schools were also different. It was agreed to use the Missouri S\&T degree requirements. Arrangements were made so that students who entered the collaborative engineering program then decided to transfer back into another major at MSU would be given credit for the General Education courses they had already taken.

The Calculus I, II, and III courses at Missouri S\&T are 4 credit hours each, while the Calculus I and II classes at MSU are 5 credit hours each and Calculus III is 3 credit hours. Differential equations is 3 credit hour course at both institutions. Linear algebra and statistics courses at both schools are 3 credit hours each. Thus, there is a net increase in 1 credit hour in the Electrical Engineering mathematics sequence at MSU. This was judged to be acceptable and the additional credit hour was added to the hours required for a Missouri S\&T BSEE degree at MSU.

The General Chemistry course at Missouri S\&T is 4 credits and there is an accompanying 1 credit hour laboratory. The General Chemistry course at MSU is 4 credit hours but there is no associated laboratory. The Electrical Engineering program at Missouri S\&T counts the Missouri S\&T Chemistry laboratory as part of the laboratory components needed to satisfy the Accreditation Board for Engineering and Technology (ABET) requirements for Electrical Engineering programs ${ }^{2}$. This led MSU to require Electrical Engineering students in the collaborative program on their campus to take General Chemistry II ( 3 credits) and the associated laboratory ( 2 credits) in addition to General Chemistry I. The General Chemistry II course and the extra 1 credit of Chemistry laboratory count as free electives in the collaborative engineering program.

Finally, Physics I and II at Missouri S\&T are 4 credit hours each, including a laboratory session, while Physics I and II at MSU are 5 credit hours each including a laboratory. This added 2 additional credits hours to the collaborative engineering program. 
Overall, the effect of these credit hour differences was that the Missouri S\&T Electrical Engineering program as offered at MSU required a minimum of approximately 131 hours for graduation as opposed to the 128 minimum hours needed at Missouri S\&T. This was due to the one extra credit hour for the mathematics sequence and one extra credit hour each for Physics I and II. While on the surface this would seem to imply a significant difference between the Missouri S\&T EE program on the Rolla campus and Missouri S\&T EE program as offered in the MSU campus. However, many students in the EE program at Missouri S\&T actually end up with more than the minimum 128 hours to graduate due to taking remedial classes and the fact that some students take a 3 credit hour class to fulfill an additional 1 credit hour graduation requirement. Thus, the 131 credit hour minimum was not believed to be that much of a burden on EE students in the collaborative program on the MSU campus.

Another issue that came up was the fact that at Missouri S\&T, the $\mathrm{C}^{++}$programming course taken by Electrical Engineering majors is 3 credits plus a 1 credit laboratory. AT MSU the $\mathrm{C}^{++}$course was only 3 credit hours with no laboratory component. However, the MSU Computer Science Department agreed to add a 1 credit hour laboratory to make the MSU class equivalent to the one at Missouri S\&T.

EE faculty at both MSU \& Missouri S\&T reviewed courses in the MSU Physics Department to see if there were any that might be appropriate substitutes for required or elective Electrical Engineering courses in the Missouri S\&T program. Electromagnetic Field (EM) Theory was one Physics course identified as a possible substitute for the EM course in the Missouri S\&T EE curriculum. Other Physics courses, particularly in optics and materials science, were considered as possible technical electives for students in the MSU EE program.

Finally, the issue of particular courses at Missouri S\&T to be offered at MSU via distance was considered. It was generally decided that the best courses to be offered by distance were lecture type courses with no associated laboratory. This would include junior level courses in the Electrical Engineering program at Missouri on topics such as control systems, communications, and electronic and photonic devices. The one exception to this was the "Controllers for Factory Automation" course at Missouri S\&T. Students in this course use computers and video monitors to remotely control processes in a simulated factory. Since the students already perform the laboratory exercises remotely and the cost of duplicating the laboratory on the MSU campus would be prohibitive, it was decided that this laboratory course could be best done on the MSU campus via distance.

\section{Summary and Conclusions}

The signing of the Memorandum of Understanding agreement in August of 2006 was followed by another year of planning, procurement of equipment, development of classroom and laboratory space, and recruitment of program faculty. The plan was to "phase in" both the Civil and Electrical Engineering programs on the MSU campus. Only freshman level classes were 
scheduled for the first year, and then sophomore level classes would be added in the second year. Junior level classes would be added in year three and senior level classes in the fourth year. Thus, the complete four-year undergraduate program in both Civil and Electrical Engineering would be in operation by the fourth year of the collaborative effort. The first Missouri S\&T engineering classes were held on the MSU campus in the fall semester of 2008. Approximately 50 students were enrolled in the program at MSU.

Faculty and administrators at both Missouri S\&T and MSU have generally expressed satisfaction with the implementation of the collaborative agreement to date. However, most also generally recognize that there are still many other details that need to be "fleshed out." In addition, there will be other issues that will no doubt surface as the program progresses.

A survey of students enrolled in the collaborative program on the MSU campus revealed that they generally expressed a high degree of favor with the program (4.3 on a scale of $1-5$, with 5 being highest). Many indicated that their circumstances would not allow them to pursue an engineering degree outside of the vicinity of Springfield and thus this program gave them the opportunity to study engineering. Others indicated that they desired to study engineering but had elected to attend MSU for other reasons, such as athletic programs, scholarships, and friends or family members already attending MSU.

The process of starting the Missouri S\&T Electrical Engineering program at MSU proved to be a challenge for the author, even though the intention was to simply duplicate the existing Missouri S\&T Electrical Engineering program on the MSU campus. Some of the lessons learned in the process are summarized below:

1. While it is a relatively simple process to sign a collaborative agreement, the details of actually implementing the agreement are far more complex than it would initially appear.

2. It also takes more time to work out implementation details than one might expect.

3. The time spent advising existing and potential students was considerably greater than the author anticipated. This was believed to be due to the fact that the program was new and many students had questions about how the program was going to function.

4. In spite of the release of what was considered to be considerable publicity about the details of the program, many students still had misunderstandings about the program. The most common of these misunderstandings was the perception the students in the program would still have to transfer to the Missouri S\&T Rolla after completing two years at MSU.

It is probably impossible to anticipate all the institutional and curriculum issues that will come up in the start of a collaborative electrical engineering program. It is hoped that the author's 
experience, as recorded here, will be of use to others considering such a collaborative effort. It should also be noted that the development of this collaborative electrical engineering program is still a "work in progress" and that procedures and policies in place at this point in time may be modified or changed as the program continues to develop.

\section{References}

1. Thamire, C., Ainane, S., Collaborative Engineering Programs at Frostburg State University, Proceedings of the 2002 American Society for Engineering Education Annual Conference and Exposition, American Society for Engineering Education.

2. Criteria for Accrediting Engineering Programs, ABET Engineering Accreditation Commission, ABET Inc., November 2007.

\section{Footnote}

*The following collaborative engineering programs were identified by the author and other members of the collaborative agreement study committee as possible models for the Missouri S \& T/MSU collaborative engineering program:

University of Arkansas Fort Smith - University of Arkansas Fayetteville

Western Kentucky University - University of Kentucky

Washington University - University of Missouri-St. Louis

University of Wisconsin-Platteville - other University of Wisconsin Colleges

University of California, Santa Cruz - Foothill College \& De Anza College

University of Wisconsin, Green Bay - University of Milwaukee

Goshen College - University of Notre Dame

Northwest Nazarene University - University of Idaho, Walla Walla College, or Seattle Pacific University

University of Maryland Eastern Shore - Salisbury State University and University of Maryland, College Park (note that the program at University of Maryland Eastern Shore became a stand alone engineering program in 2007)

Frostburg State University - University of Maryland, College Park

Note that the above list does not include all collaborative engineering programs, simply those identified by the collaborative committee as possible models. 